\title{
Sistem Presensi Online Menggunakan Arsitektur Pengembangan Perangkat Lunak Model-View-Viewmodel
}

\author{
Adha Setiawan Wiyana ${ }^{1 *}$, M. Ihsan Alfani Putera ${ }^{2}$, Sri Rahayu Natasia ${ }^{3}$ \\ ${ }^{1,2,3}$ Program Studi Sistem Informasi, Institut Teknologi Kalimantan, Balikpapan, Kalimantan Timur \\ Email: ${ }^{1 *}$ adhasetiawanwiyana@ gmail.com, ${ }^{2}$ ihsanalfani@lecturer.itk.ac.id, ${ }^{3}$ natasia.ayu@ lecturer.itk.ac.id
}

(Naskah masuk: 1 Agu 2021, direvisi: 18 Okt 2021, 29 Okt 2021, diterima: 2 Nov 2021)

\begin{abstract}
Abstrak
PT. Lintasmaya Network Samarinda adalah perusahaan yang bergerak di bidang jasa dengan memberikan layanan IT Support kepada perusahaan lain. Sebagai perusahaan yang bergerak di bidang jasa, PT. Lintasmaya Network Samarinda perlu memastikan untuk dapat memberikan layanan terbaik kepada konsumen dengan memperhatikan kinerja karyawan. Agar hal tersebut dapat tercapai, maka solusi yang dipilih oleh PT. Lintamaya Network Samarinda adalah membangun sistem presensi berbasis aplikasi mobile. Hanya saja karena PT. Lintasmaya Network Samarinda tidak memiliki kemampuan dan pengalaman dalam mengembangkan sebuah aplikasi mobile, sistem presensi tersebut tidak dapat berjalan dengan baik. Berangkat dari masalah tersebut, maka diadakan penelitian pengembangan sistem presensi berbasis aplikasi mobile dengan menggunakan metode pengembangan perangkat lunak Personal Extreme Programming (PXP) dan arsitektur Model-View-Viewodel (MVVM). Metode pengembangan perangkat lunak PXP terdiri dari tujuh proses yaitu requirement, planning, iteration initialization, design, implementation, system testing, dan retrospective. Sedangkan aristektur MVVM adalah penulisan kode yang dibagi menjadi tiga bagian terdiri dari view, viewmodel, dan model. Adapun hal lain yang menjadi perhatian dalam penelitian ini adalah penerapan IMEI untuk mengenali perangkat, GPS untuk mendapatkan lokasi, dan JWT Authentication untuk keamanan fitur. Melalui penerapan tersebut, sistem dapat memberikan hal positif seperti data yang akurat dan penggunaan fitur yang terbatas hanya untuk pihak perusahaan.
\end{abstract}

Kata Kunci: Android, MVVM, PXP, Sistem Presensi.

\section{Online Presence System Development Using Model-View- Viewmodel Software Development Architecture}

\begin{abstract}
PT. Lintasmaya Network Samarinda is a company engaged in the service sector by providing IT Support services to other companies. As a company engaged in service, PT. Lintasmaya Network Samarinda needs to ensure that it can provide the best service to consumers by paying attention to employee performance. To achive that aim, the solution chosen by PT. Lintamaya Network Samarinda is building a mobile application-based presence system. It's just because PT. Lintasmaya Network Samarinda does not have the ability and experience in developing a mobile application, the presence system cannot run properly. Based on this problem, a research was conducted on the development of a mobile application-based presence system using the Personal Extreme Programming (PXP) software development method and the Model - View - Viewodel (MVVM) architecture. PXP software development method consists of seven processes, namely requirements, planning, iteration initialization, design, implementation, system testing, and retrospective. While the MVVM architecture is writing code which is divided into three parts consisting of view, viewmodel, and model. Other concerns in this research are the application of IMEI to identify the device, GPS to get location, and JWT Authentication for security features. Through that implementation, the system is now able to provide positive things such as accurate dat and, limited use of features only for the company.
\end{abstract}

Keywords: Android, MVVM, PXP, Presence System.

TEKNIKA, Volume 10(3), November 2021, pp. 214-224

DOI: $10.34148 /$ teknika.v10i3.398

ISSN 2549-8037, EISSN 2549-8045 


\section{PENDAHULUAN}

Perkembangan teknologi sudah menjadi hal yang sangat umum dan mudah untuk diamati. Perkembangan ini terjadi diberbagai macam bidang dan berbagai macam aspek, selaras dengan jalannya perkembangan ilmu pengetahuan. Hal ini dapat dibuktikan dengan bukti sejarah pada tahun 1750 hingga 1930 dimana mesin uap dan kereta api menjadi revolusi industri pada saat itu. Lalu dilanjutkan dengan 1870 hingga 1900 dimana listrik, alat komunikasi serta kimia dan minyak menjadi hal baru yang digemari oleh masyarakat dan industri dunia. Hingga akhirnya masuk pada tahun 1960 hingga sekarang dimana internet sudah menjadi kebutuhan sehari-hari untuk masyarakat dunia [1].

Pada tahun 2021 perkembangan teknologi kini sudah menjadi lebih pesat dengan hadirnya revolusi industri 4.0. Mengutip dari penelitian yang sudah dilakukan oleh Venti Eka pada tahun 2018, Kementrian Perindustrian sudah memiliki rencana agar Indonesia bisa mendapatkan untung dari revolusi industri 4.0. Adapun langkah tersebut dimulai dari mendorong sumber daya manusia lebih berkompeten dalam bidang internet of things (IoT) hingga memfasilitasi pengembangan start up di Indonesia [1].

Antusias dari revolusi industri 4.0 tidak hanya terjadi pada sisi pemerintah saja. Pada dunia industri sudah banyak perusahaan/instansi/lembaga/organisasi yang mau melalukan investasi pada bidang teknologi, khususnya pada sisi perkembangan perangkat lunak. Salah satu contohnya penelitian yang dilakukan oleh Panji Rachmat untuk membuat sistem presensi berbasis Android, dimana pada hasil penelitian tersebut implementasi sistem presensi berbasis Android pada Universitas Islam Riau memberikan dampak baik karena sistem dapat mempermudah proses pendataan kehadiran [2].

Hasil dari penelitian di Universitas Islam Riau tersebut tidak jauh berbeda dengan penelitian di beberapa tempat. Jika dikelompokan ke dalam dua device, penelitian sistem presensi pada device Android pernah dilakukan di dua perusahaan. Pertama oleh Ardian Permana untuk perusahaan PT. Pelabuhan Indonesia III [3]. Kedua dilakukan oleh Arafat Febriandirza pada PT. Duta Hidayah [4]. Sedangkan pada web, penelitian sistem presensi pernah dilakukan oleh Subiantoro pada kantor Kecamatan Purwodadi [5]. Penelitian-penelitian tersebut mendapatkan hasil yang baik di mana sistem kehadiran dapat mempercepat proses pendataan kehadiran masuk dan pulang karyawan. Selain itu adapun keuntungan lain yang didapat seperti akses informasi yang mudah, resiko kesalahan yang kecil, dan lainnya [5].

Berangkat dari kondisi yang telah dijelaskan di atas, maka hal serupa telah dilakukan oleh perusahaan Lintasmaya Network Samarinda pada sistem kehadiran mereka. PT. Lintasmaya Network sendiri adalah perusahaan yang bergerak di bidang jasa dengan memberikan layanan IT Support kepada perusahaan lain. Perusahaan ini berada di kota Samarinda, provinsi Kalimantan Timur. Karena PT. Lintasmaya Network Samarinda bergerak pada bidang jasa, maka kinerja dari sumber daya manusia sudah menjadi aspek yang perlu mendapat perhatian khusus dari perusahaan tersebut [6].
Bergeraknya Lintasmaya Network pada bidang jasa dan hadirnya tema penelitian untuk sistem presensi karyawan, membuat PT. Lintasmaya Network terdorong untuk dapat mengembangkan sistem presensi dengan dua fokus utama. Fokus pertama adalah keamanan dan fokus kedua adalah maintainability, dimana sistem mudah untuk dirawat dan dikembangkan oleh perusahaan. Hadirnya kedua fokus ini akan menjadi pembeda dari penelitian yang sudah ada, sekaligus kunci agar PT. Lintasmaya Network dapat mengawasi kinerja karyawan sehingga dapat berkontribusi penuh kepada perusahaan [6].

Adapun implementasi teknologi dan metode yang digunakan agar kedua fokus tercapai adalah PXP yang merupakan bentuk lain Extreme Programming $(X P)$ dimana $P X P$ dibuat khusus untuk pengembangan sistem oleh satu orang [7]. Arsitektur MVVM yang merupakan salah model desain pengembangan perangkat lunak yang membuat user interface terpisah dengan back end dari sistem [8]. Sedangkan pada fokus keamanan implementasi akan berfokus pada penggunaan IMEI perangkat, GPS, dan JWT Authentication.

\section{METODOLOGI PENELITIAN}

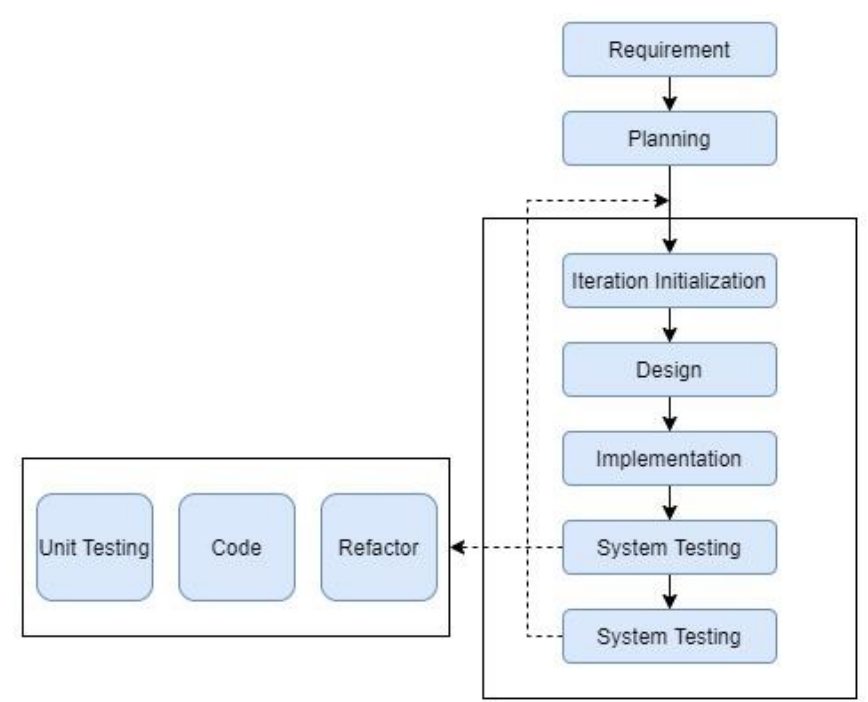

Gambar 1. Alur Penelitian dari Sistem Presensi PT. Lintasmaya Network

Implementasi metode pengembangan perangkat lunak PXP didasarkan pada penelitian tahun 2018 yang telah dilakukan oleh Gita Indah. Hasil dari implementasi metode PXP pada penelitian teresbut berjalan dengan baik, karena proses metode PXP memberikan keuntungan berupa mudahnya proses pengembangan sistem. Ketika terjadi perubahan terhadap proses requirement, peneliti dapat cepat menyesuaikan perubahan tersebut pada tahap implementasi, sehingga peneliti dapat dengan cepat menghadirkan sistem informasi bagi perpustakaan [7].

Melalui penelitian yang sudah pernah dilakukan tersebut, maka implementasi PXP pada sistem presensi dianggap ideal. Metode PXP adalah metode turunan dari Extreme 
Progromming (XP) yang mana XP sendiri adalah salah satu model dari metode Agile. Perbedaan metode PXP dan XP ada pada penyesuaian cara kerja, yang mana metode PXP dibuat khusus untuk satu orang. Melalui penyesuaian tersebut maka implementasi metode PXP terdiri dari tujuh proses utama seperti terlihat pada Gambar 1. Proses pertama akan dimulai dari requirement lalu dilanjutkan dengan planning, design, implementation, system testing hingga proses terakhir yaitu retrospective [7].

\section{A. Requirement}

Tahapan pertama dari PXP pada sistem kehadiran adalah tahap requirement. Tahap ini dikerjakaan dengan tujuan untuk mendapatkan kebutuhan dasar dari sistem yang dikembangkan ke depannya, mulai dari apa saja fitur yang dibuat dan bagaimana detail dari fitur yang ada pada sistem tersebut. Selain mendapatkan semua kebutuhan dasar seperti yang telah disebutkan sebelumnya, tujuan lain dari tahapan ini adalah menilai apa saja sekiranya masalah yang bisa dihadapi, berapa lama waktu yang dibutuhkan, serta alat bantu saja yang diperlukan untuk membuat sistem tersebut. Tahapan requirement dikerjakan dengan menggunakan dua cara. Pertama adalah sesi wawancara kepada mitra dan kedua, studi literatur untuk melihat detail dari kebutuhan sistem [7].

\section{B. Planning}

Tahapan kedua adalah tahapan planning. Tahapan ini dikerjakan dengan memperhatikan hasil dari sesi wawancara pada tahap requirement. Selain dari memperhatikan hasil wawancara, proses lain yang dapat dikerjakan adalah memperhatikan bagaimana sistem yang ada sekarang sudah berjalan. Melalui dua proses tersebut maka hasil dari tahap planning adalah rancangan sistem baru pada tiap fitur dengan memperhatikan fokus-fokus yang diinginkan mitra. Apabila rancangan sudah sesuai dengan fokus yang disebutkan sebelumnya maka proses ini dapat dilanjutkan menuju tahapan Iteration Initialization dan begitu pula sebaliknya. Pada penelitian dari sistem presensi PT. Lintasmaya Network, hasil dari tahap planning dibuat dalam bentuk flowchart agar mudah dipahami. Melalui proses inilah proses pengembangan menjadi ideal karena proses pengembangan didokumentasikan sehingga bisa dijadikan pembelajaran ke depannya [7].

\section{Iteration Initialization}

Tahap ketiga PXP pada sistem presensi adalah Iteration Initialization. Tahap ini dikerjakan dengan tujuan untuk membuat detail dari jalan proses pengembangan tiap iterasi. Selain membuat detail pengerjaan, tahapan ketiga ini juga merupakan tahapan untuk memastikan berapa lama tiap iterasi berjalan pada masing-masing proses. Hal yang perlu diperhatikan pada tahapan ini di antaranya adalah prioritas, tingkat kesulitan, dan alur sistem. Berdasarkan dari penjelasan di atas maka hasil dari implementasi metode iteration initialization dibuat dalam bentuk tabel dengan detail kegiatan terurut dilengkapi dengan estimasi waktu pengerjaan [7].

\section{Design}

Tahap keempat PXP pada sistem kehadiran adalah design. Hasil dari tahap ini adalah sebuah gambaran yang akan dilihat oleh user. Tahap ini dikerjakan dengan menggunakan alat bantu/tool seperti Adobe XD, Figma, dan Balsamiq. Pada penelitian ini, proses design dikerjakan dengan menggunakan figma, karena pemakaian yang mudah. Selain dari memberikan gambaran tampilan kepada user, tahap design memberikan keuntungan lain seperti membantu peneliti melihat data apa saja yang akan ditampilkan. Serta membantu proses implementasi kode berjalan lebih cepat karena design yang dibutuhkan sudah dikerjakan pada proses terpisah [7].

\section{E. Implementation}

Tahap kelima pada metode pengembangan PXP adalah implementation. Tahap ini adalah proses pengembangan sistem dengan menyesuaikan rancangan yang sudah dibuat [7]. Pada tahap implementasim peneliti menggunakan dua alat bantu yaitu bahasa pemrograman Kotlin dan IDE Android Studio. Agar proses implementasi berjalan maksimal, maka pada proses inilah peneliti menerapkan arsitektur MVVM dengan memperhatikan fokus keamanan dan maintainability.

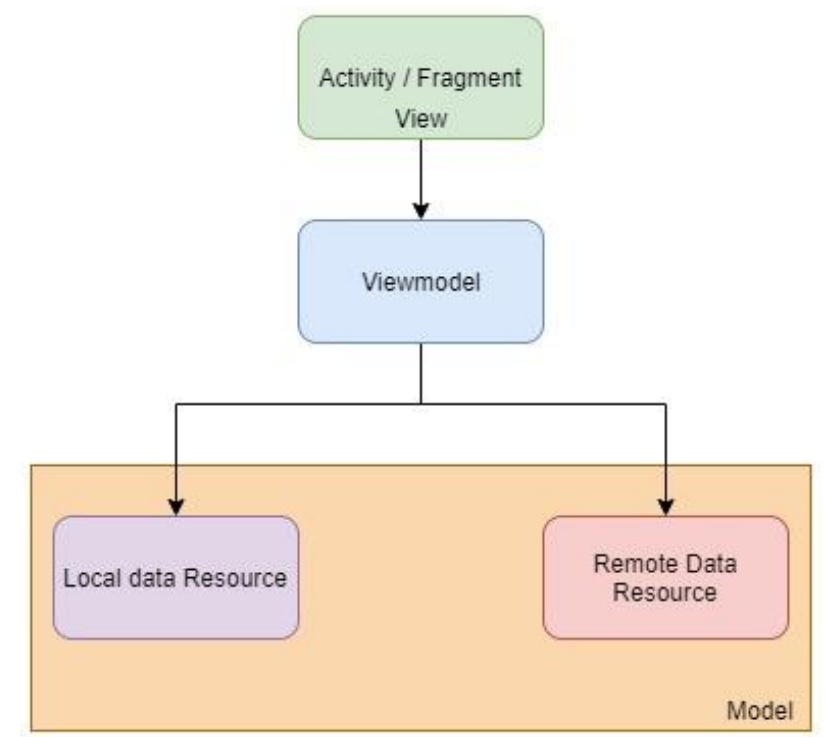

Gambar 2. Design Pattern Model-View-Viewmodel

Sama seperti implementasi PXP, pemilihan implementasi arsitektur MVVM pada sistem kehadiran didasarkan dari penelitian lain. Implementasi MVVM sudah pernah dilakukan untuk membangun sistem yang membuat diagnosis kondisi pendengaran seseorang. Implementasi tersebut dilakukan pada tahun 2019 oleh Sheikh Waseem. Hasil dari implementasi tersebut menyatakan implementasi MVVM bisa menjadi solusi untuk pengembangan sistem dalam jangka waktu panjang karena penulisan kode yang terbagi menjadi tiga bagian sehingga proses pengembangan menjadi lebih mudah [8].

Berdasarkan Gambar 2, implementasi MVVM dibagi menjadi tiga bagian. Bagian pertama adalah model yang bertanggung jawab untuk menjalankan API dan mengatur 
kesediaan data pada repository. Bagian kedua adalah viewmodel yang bertanggung jawab untuk memperhatikan ketersediaan data dan memberikan respon dari API. Bagian ketiga adalah view yang bertanggung jawab untuk mengatur tampilan yang akan dilihat oleh user. Melalui penulisan kode secara terpisah seperti penejalasan yang telah disampaikan, membuat sistem menjadi lebih mudah untuk dikembangkan dan dirawat jika terjadi hal yang tidak diinginkan[8].

Adapun proses implementasi dilanjutkan dengan menerapkan tiga metode keamanan yang didasarkan pada penelitian lain. Metode pertama adalah penggunaan IMEI untuk mengetahui device yang digunakan, sehingga ketika karyawan ingin mengganti device, karyawan tersebut harus melapor kepada perusahaan. Penggunaan IMEI pada sistem kehadiran dianggap ideal, karena kombinasi angka yang acak serta beragam dan dapat digabungkan dengan metode keamanan lain, yang dilakukan pada penelitian 2018 oleh Pavan Sai [9].

Metode selanjutnya adalah metode untuk melacak lokasi karyawan dengan menggunakan GPS. Metode ini dianggap efektif karena sudah diterapkan pada penelitian lain seperti penelitian AbsenLoc pada tahun 2021 oleh Jemy Agung. Pada penelitian tersebut, hasil implementasi pada sistem presensi dianggap efektif dan sudah dapat memberikan manfaat yaitu proses pendataan kehadiran yang singkat dan mudah [10].

Metode keamanan terakhir pada sistem presensi PT. Lintasmaya Network adalah JWT Authentication. Metode ini bekerja dengan memberikan sebuah token kepada masingmasing user, sehingga semua fitur pada sistem kehadiran benar-benar hanya digunakan oleh pihak yang mimiliki kepentingan. Implementasi dari JWT Authentication dianggap cukup efektif karena sudah terbukti dapat menuntaskan masalah interoperabilitas, sehingga sistem dapat bertukar informasi satu sama lain [11].

\section{F. System Testing}

Bagian keenam dari implementasi PXP pada sistem kehadiran adalah system testing. Proses uji sistem dilakukan dengan tujuan untuk melihat bagaimana sistem berjalan dengan skenario kejadian tertentu. Proses ini akan berjalan dengan menggunakan metode uji sistem black box. Adapun implementasi metode uji sistem black box dikerjakan pada tiap iterasi agar hasil yang didapatkan menjadi lebih teliti [7].

\section{G. Restrospective}

Tahap terakhir pada PXP adalah tahap restrospective. Tahap ini bertujuan untuk melihat kesesuaian proses implementasi dari dengan rancangan yang sudah dibuat. Tahap ini dilakukan pada di semua iterasi. Apabila sudah sesuai maka proses iterasi tersebut akan dianggap selesai dan peneliti dapat berlanjut mengerjakan iterasi pada fitur-fitur lain [7].

\section{HASIL DAN PEMBAHASAN}

Berikut adalah detail dari implementasi metode pengembangan PXP dan aristektur MVVM. Agar hasil dapat sesuai dengan fokus yang diinginkan mitra, maka hal lain yang harus diperhatikan adalah penggunaan metode get IMEI, get location \& JWT Authentication.

\section{A. Requirement}

Berikut adalah hasil proses requirement dengan melakukan dua proses. Proses adalah wawancara kepada mitra untuk mendapatkan kebutuhan dasar dari sistem kehadiran. Proses kedua adalah studi literatur untuk mendapatkan detail dari tiap fitur yang ada pada sistem kehadiran.

Tabel 1. Daftar Tabel Fitur Kehadiran

\begin{tabular}{cccl}
\hline No & \multicolumn{3}{c}{ Kode } \\
Fitur & $\begin{array}{c}\text { Nama } \\
\text { Fitur }\end{array}$ & \multicolumn{1}{c}{ Deskripsi Fitur } \\
& FU-01 & $\begin{array}{l}\text { Log in / } \\
\text { Sign in }\end{array}$ & $\begin{array}{l}\text { Sistem keamanan dengan } \\
\text { memastikan bahwa hanya } \\
\text { dapat digunakan oleh pihak } \\
\text { tertentu. }\end{array}$ \\
\hline 2 & FU-02 & $\begin{array}{l}\text { Admin } \\
\text { contact }\end{array}$ & $\begin{array}{l}\text { Menghubungi admin melalui } \\
\text { send email, sebagai langkah } \\
\text { untuk menyampaikan masalah } \\
\text { jika akun user bermasalah. }\end{array}$ \\
\hline 3 & FU-03 & Presence & $\begin{array}{l}\text { Pencatatan kehadiran tanggal, } \\
\text { waktu dan kegiatan karyawan. }\end{array}$ \\
\hline 4 & FU-04 & Absence & $\begin{array}{l}\text { Pencatatan waktu dan tanggal } \\
\text { selesai bekerja. }\end{array}$ \\
\hline 5 & FU-05 & $\begin{array}{l}\text { Track } \\
\text { record }\end{array}$ & $\begin{array}{l}\text { Menampilkan data detail } \\
\text { kinerja karyawan dalam } \\
\text { bentuk waktu, tanggal dan } \\
\text { kegiatan. }\end{array}$ \\
\hline 6 & FU-06 & Profile & Menampilkan data diri user. \\
\hline 7 & FU-07 & $\begin{array}{l}\text { Password } \\
\text { change }\end{array}$ & $\begin{array}{l}\text { Sistem keamanan dengan } \\
\text { memastikan bahwa hanya } \\
\text { dapat digunakan oleh pihak } \\
\text { tertentu. }\end{array}$ \\
\hline & & &
\end{tabular}

Berdasarkan Tabel 1, proses pengembangan sistem presensi memiliki tujuh buah fitur. Tiap fitur dikerjakan dalam iterasi terpisah. Setiap iterasi memiliki detail yang berbeda dengan iterasi lain. Jika pengerjaan iterasi sudah sesuai dengan yang diinginkan mitra maka proses pengembangan dapat dilanjutkan menuju iterasi lain. Jika yang terjadi sebaliknya maka iterasi akan disesuaikan dengan yang diinginkan mitra. Adapun detail dari tiap fitur dapat dilihat dari salah satu tabel pada iterasi fitur seperti berikut

Tabel 2. Detail Fitur Log In Pada Sistem Presensi

\begin{tabular}{ccll}
\hline $\begin{array}{c}\text { Kode } \\
\text { Fitur }\end{array}$ & $\begin{array}{c}\text { Nama } \\
\text { Fitur }\end{array}$ & Deskripsi Fitur & \multicolumn{1}{c}{ Detail Fitur } \\
\hline FU- & Log in & $\begin{array}{l}\text { Sebuah fitur yang } \\
\text { memungkinkan }\end{array}$ & $\begin{array}{l}\text { Input email, } \\
\text { password \& IMEI }\end{array}$ \\
\cline { 3 - 3 } & & $\begin{array}{l}\text { Input } \text { IMEI } \\
\text { user untuk }\end{array}$ & mengakses sebuah \\
& & dilakukan secara \\
& & & otomatis \\
\hline
\end{tabular}




\begin{tabular}{ll} 
mengenali user & Akses data \\
melalui input & penggunaan \\
identitas tertentu. & dengan email, \\
password \& IMEI & Generate token \\
& untuk menjadi \\
akses user kepada & fitur lain \\
\hline & Menyimpan \\
& respon dari \\
pencarian data & user
\end{tabular}

Berdasarkan Tabel 2 rancangan pada fitur $\log$ in akan memiliki lima detail. Masing-masing detail dibuat dengan memperhatikan fokus yang sudah diinginkan mitra. Pada fitur log in, fokus yang diperhatikan adalah fokus keamanan. Fokus ini dapat diwujudkan dengan menambahkan masukan data secara otomatis dengan menggunakan get IMEI sehingga sistem dapat mengenali device apa yang digunakan oleh user. Keuntungan dari penggunaan metode get IMEI adalah bisa memberikan fokus lain, yaitu fokus akurasi data sehingga dapat meminimalkan kemungkinan masukan data yang diberikan salah.

Tabel 3. Detail Fitur Admin Contact Pada Sistem Presensi

\begin{tabular}{ccll}
$\begin{array}{c}\text { Kode } \\
\text { Fitur }\end{array}$ & $\begin{array}{c}\text { Nama } \\
\text { Fitur }\end{array}$ & \multicolumn{1}{c}{ Deskripsi Fitur } & Detail Fitur \\
\hline FU- & Admin & $\begin{array}{l}\text { Sebuah fitur yang } \\
\text { dapat membantu } \\
02\end{array}$ & $\begin{array}{l}\text { Akses halaman } \\
\text { Contact } \\
\end{array}$ \\
& & $\begin{array}{l}\text { penger ketika terjadi } \\
\text { kendala pada akun }\end{array}$ & $\begin{array}{l}\text { email dengan } \\
\text { sebuah button }\end{array}$ \\
\hline
\end{tabular}

Berdasarkan Tabel 3 agar fokus maintainability dapat bisa menjadi lebih maksimal, maka peneliti dapat membuat sebuah fitur sederhana. Fitur tersebut nantinya akan berguna untuk menghubungkan user dan admin ketika terjadi masalah sehingga kedepannya mitra memiliki refrensi dan data apa saja yang harus diperbaiki. Selain itu juga memiliki referensi dan data bagaimana sistem bisa dikembangkan menjadi lebih baik berdasarkan dari masukan yang diberikan oleh user.

\section{B. Planning}

Proses selanjutnya pada implementasi PXP adalah proses planning. Proses ini dikerjakan dengan memperhatikan hasil dari proses requirement. Selain memperhatikan proses pertama, hal lain yang dapat menjadi acuan ketika mengerjakan proses planning adalah melihat dari sistem yang sudah ada serta memperhatikan metode yang sekiranya dapat memenuhi fokus pengembangan yang diinginkan mitra.

Berdasarkan Gambar 3 agar fokus keamanan dari fitur log in dapat berjalan lebih baik, maka pada bagian B proses log in perlu dibuat metode untuk mengamankan API yang ada pada sistem kehadiran. Metode pengamanan ini dilakukan dengan menggunakan JWT Authentcation. Hadirnya metode pengamanan ini akan memberikan keuntungan untuk bisa melakukan hal seperti pemisahan otoritas antar akun seperti admin dan user sehingga sistem benar-benar digunakan oleh pihak yang memiliki kepentingan saja.
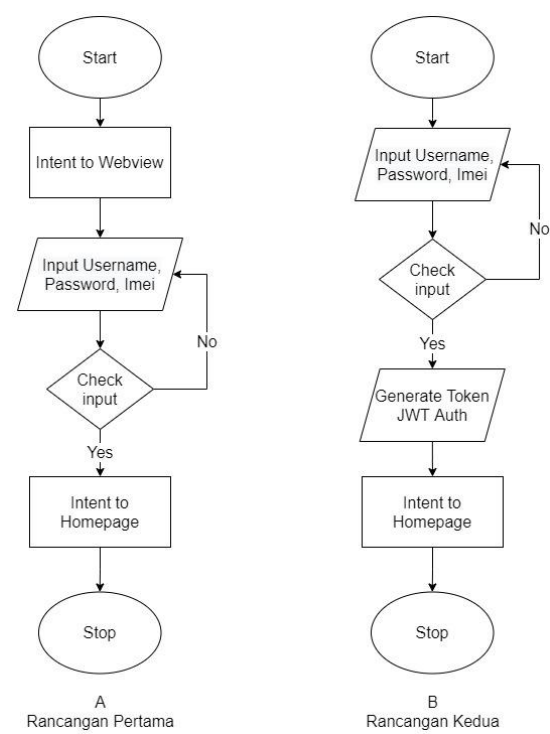

Gambar 3. Rancangan Baru Fitur Log In Pada Sistem Presensi

Gambar 3 bagian A adalah flowchart dari fitur log in yang telah dimplementasikan dan berjalan sekarang. Pada fitur yang sedang berjalan sistem kehadiran menjadi lebih sulit untuk dikembangkan karena model tampilan yang menggunakan teknologi webview dan bukan tampilan native dari sistem. Kerugian lain dari rancangan ini juga terletak pada sisi keamanan, karena sistem hanya dapat mengenali user tanpa bisa mengenali device yang digunakan oleh user.
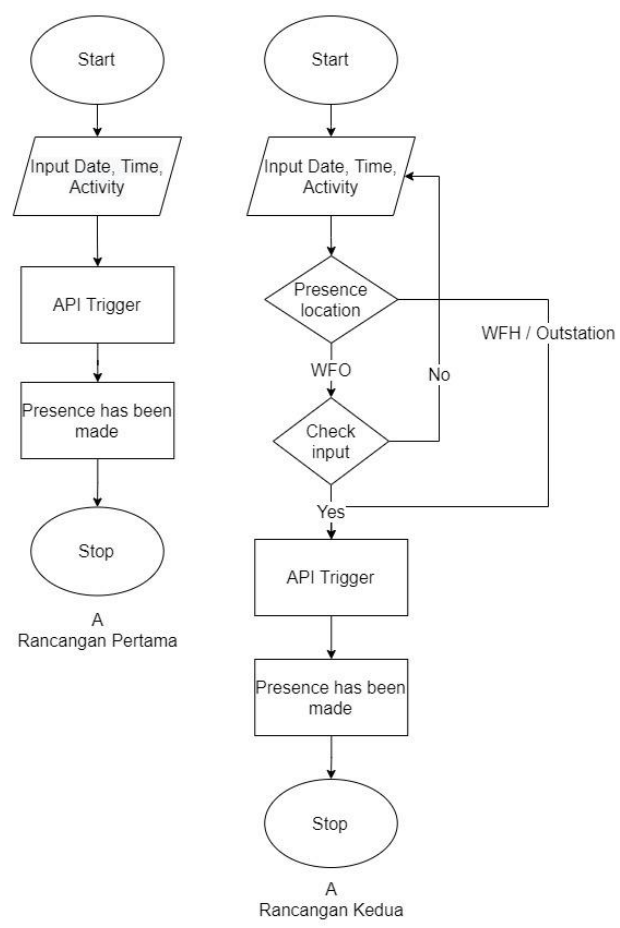

Gambar 4. Rencana Baru Fitur Presence Pada Sistem Presensi 
Berdasarkan Gambar 4 bagian B metode yang perlu diperhatikan selama proses implementasi adalah metode get location. Metode ini memberikan keuntungan kepada sistem agar bisa memastikan lokasi keberadaan user. Selain dari pada itu keuntungan lain dari penggunaan metode get location adalah peneliti dapat membuat fungsi kecil yang bisa meningkatkan keamanan seperti perhitungan jarak dan membuat pilihan untuk presensi di kantor dan di luar kantor.

Pada Gambar 4 bagian A adalah rancangan dari fitur presence yang kini digunakan. Proses pada rancangan ini mimiliki banyak kekurangan. Dimulai dari tidak adanya metode keamanan seperti pencatatan lokasi serta tidak dilengkapi dengan metode untuk melakukan kehadiran dengan metode yang berbeda sehingga akurasi data yang didapatkan oleh mitra tidak detail.

\section{Iteration Initialization}

Proses selanjutnya dari implementasi model pengermbangan PXP adalah iteration intialization. Proses ini dikerjakan dengan menentukan detail kegiatan yang akan dilakukan pada masing-masing iterasi. Agar proses pengerjaan iterasi dapat berjalan lebih efektif, maka selain membuat detail dari apa saja yang dikerjakan, peneliti juga perlu membuat urutan setiap detail kerjaan lengkap dengan estimasi waktu pengerjaan iterasi.

Tabel 4. Iterasi Fitur Log In Pada Sistem Presensi

\begin{tabular}{|c|c|c|c|}
\hline \multicolumn{4}{|c|}{ Log in } \\
\hline No & $\begin{array}{l}\text { Kode } \\
\text { Story }\end{array}$ & Deskripsi & Estimasi \\
\hline 1 & LO-01 & $\begin{array}{l}\text { Wawancara sistem terdahulu } \\
\text { kepada mitra terkait sistem } \\
\text { yang sudah ada }\end{array}$ & 1 Hari \\
\hline 2 & LO-02 & Studi literatur & 1 Hari \\
\hline 3 & LO-03 & $\begin{array}{l}\text { Membuat model As-Is pada } \\
\text { model login terbaru }\end{array}$ & 1 Hari \\
\hline 4 & LO-04 & $\begin{array}{l}\text { Konfirmasi rancangan model } \\
\text { As-Is kepada mitra }\end{array}$ & 1 Hari \\
\hline 5 & LO-05 & Membuat tampilan Mock up & 2 Hari \\
\hline 6 & LO-06 & $\begin{array}{l}\text { Membuat API dengan } \\
\text { memperhatikan metode JWT } \\
\text { Authentication dan pengujian } \\
\text { API }\end{array}$ & 6 Hari \\
\hline 7 & LO-07 & $\begin{array}{l}\text { Implementasi Login dengan } \\
\text { menggunakan metode get } \\
\text { IMEI dan arsitektur MVVM }\end{array}$ & 7 Hari \\
\hline 8 & LO-08 & Pengujian Sistem $\log$ in & 1 Hari \\
\hline
\end{tabular}

Berdasarkan Tabel 4, hasil tabel iteration initialization didapatkan dengan memperhatikan rancangan dari kebutuhan sistem pada proses pertama dan kedua. Karena setiap sistem memiliki kebutuhan dan detail yang berbeda maka proses implementasi pada tiap iterasi akan berbeda. Jika dalam proses perancangan, fitur tersebut tidak membutuhkan data dari basis data, maka proses pengerjaan dapat berjalan lebih singkat. Proses pengerjaan yang singkat ini terjadi karena peneliti tidak perlu membuat API untuk fitur tersebut sehingga fitur dapat berjalan tanpa koneksi internet nantinya. D. Design

Proses keempat pada metode PXP adalah design. Seperti yang telah dijelaskan sebelumnya, proses ini dikerjakan dengan menggunakan sebuah alat bantu berupa software. Pada penelitian ini hasil proses design dikerjakan dengan menggunakan software bernama Figma. Berikut adalah salah satu hasil dari proses design pada iterasi log in dengan menggunakan Figma.

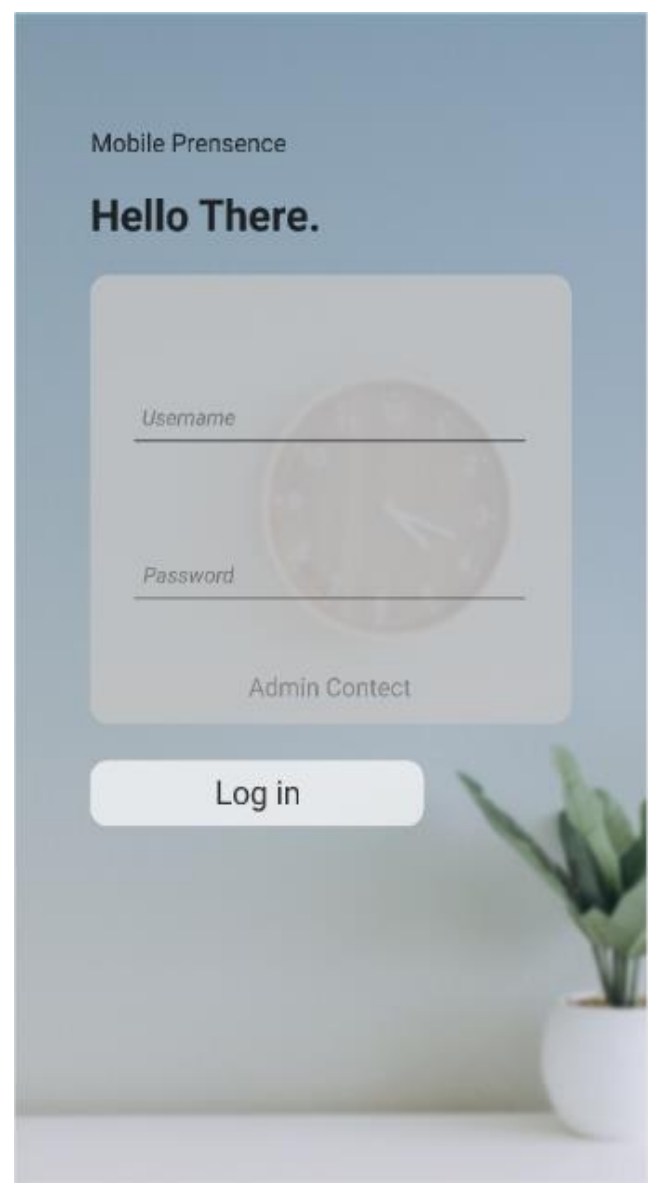

Gambar 5. Desain Baru Fitur Log In Pada Sistem Presensi

Berdasarkan Gambar 5, tampilan dari fitur log in memiliki desain yang bersifat minimalis. Desain dari fitur $\log$ in telah disesuaikan dengan rancangan yang sudah dibuat sebelumnya, sehingga masukan data secara manual dari user hanya ada pada email dan password. Sedangkan pada imei masukan data tidak diperlukan karena proses masukan data imei terjadi secara otomatis.

\section{E. Implementation}

Proses selanjutnya dari metode pengembangan PXP adalah implementation. Proses ini dikerjakan dengan menggunakan arstitektur MVVM. Selain dari arsitektur MVVM, pada proses implementasi proses penulisan kode juga berfokus pada implementasi IMEI, lokasi user, dan JWT Authentication. Proses implementasi dikerjakan dengan menggunakan bahasa pemrograman Kotlin dengan IDE 
Android Studio. Berikut adalah salah satu hasil dari implementasi MVVM pada iterasi $\log$ in.

Tabel 5. Implementasi Fitur Log In Pada Sistem Presensi

\begin{tabular}{|c|c|c|}
\hline Layer & Kelas & Hasil \\
\hline \multirow{28}{*}{ Model } & ApiService & $b$ \\
\hline & \multirow[t]{19}{*}{ LoginObject } & object LoginObject \{ \\
\hline & & data class \\
\hline & & LoginResponse( \\
\hline & & val data_user: \\
\hline & & DataUser, \\
\hline & & val massage: String, \\
\hline & & val success: Boolean, \\
\hline & & val token: String \\
\hline & & \\
\hline & & data class DataUser( \\
\hline & & val id_user: Int, \\
\hline & & val username: String, \\
\hline & & val email: String, \\
\hline & & val name: String, \\
\hline & & val division: String, \\
\hline & & val address: String, \\
\hline & & val role: String, \\
\hline & & val picture: String \\
\hline & & )$\}$ \\
\hline & LoginReposito & //API Trigger \\
\hline & $r y$ & fun login \\
\hline & & (email:String, \\
\hline & & password:String, \\
\hline & & imei : BigInteger) : Singl \\
\hline & & $\begin{array}{l}\text { e<LoginObject. LoginRes } \\
\text { ponse }>\{\end{array}$ \\
\hline & & return \\
\hline & & $\begin{array}{l}\text { apiservice.login(email } \\
\text {, password, imei)\} }\end{array}$ \\
\hline \multirow{15}{*}{$\begin{array}{l}\text { Viewm } \\
\text { odel }\end{array}$} & \multirow{15}{*}{$\begin{array}{l}\text { LoginViewmo } \\
\text { del }\end{array}$} & private val \\
\hline & & loginResponse:MutableL \\
\hline & & iveData<UiState<Logino \\
\hline & & bject.LoginResponse>> \\
\hline & & = MutableLiveData() \\
\hline & & fun \\
\hline & & getLoginResponse () : Liv \\
\hline & & ect. LoginResponse $>>\{$ re \\
\hline & & turn loginResponse\} \\
\hline & & fun login(email: \\
\hline & & String, password: \\
\hline & & String, imei: \\
\hline & & BigInteger $)\{$ \\
\hline & & //Uistatus \\
\hline & & loginResponse.postValu \\
\hline
\end{tabular}

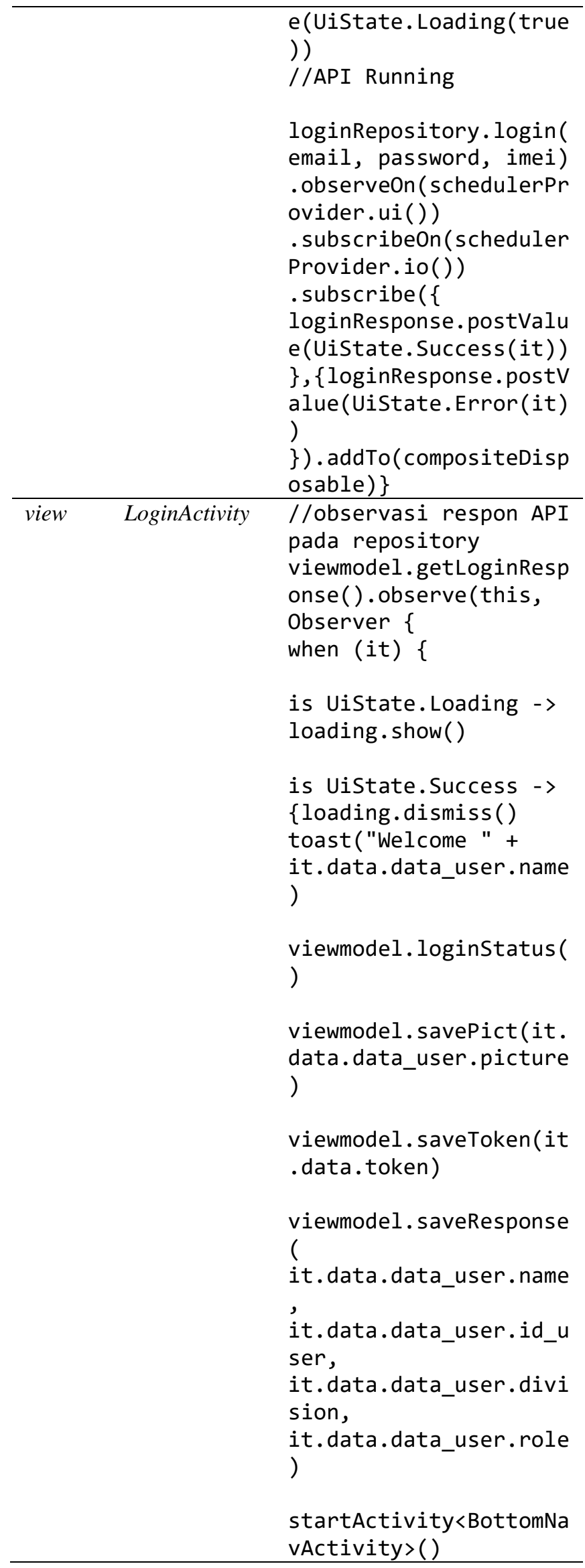




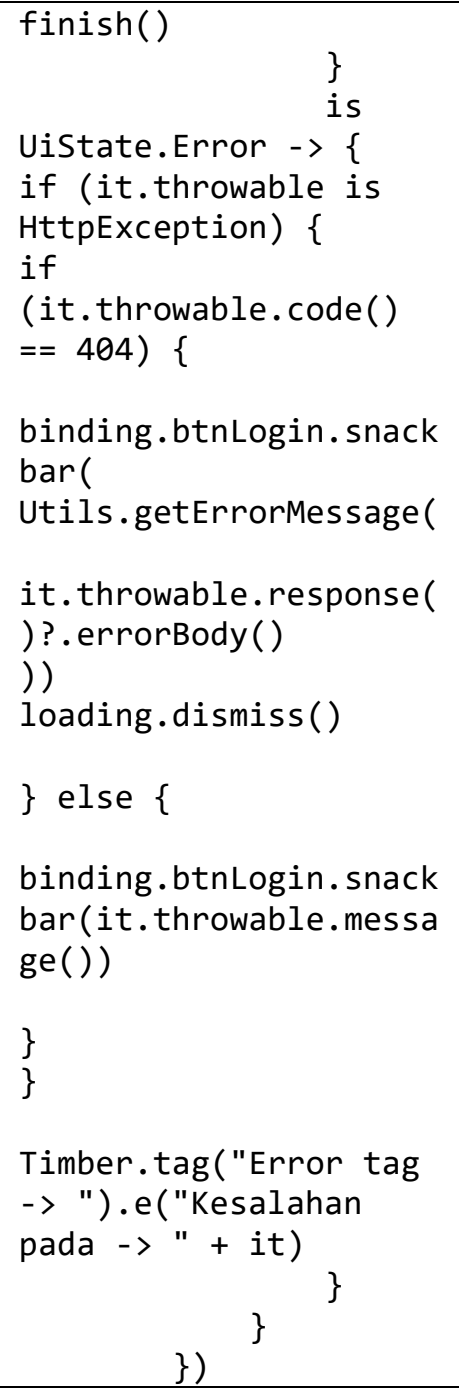

Berdasarkan Tabel 5 implementasi dari fitur $\log$ in dikerjakan dengan arsitektur MVVM agar nantinya mitra bisa dengan mudah merawat dan mengembangkan sistem kehadiran sehingga fokus maintainability dapat tercapai. Implementasi kode terbagi menjadi tiga bagian. Bagian pertama model, dimana bagian ini betugas untuk menjalankan API dengan kode fun login (masukan data dari user). Setelah API berjalan dan sistem mendapatkan respon, maka respon tersebut disimpan ke dalam sebuah objek yang memiliki dua data class dalam bentuk kode data class loginResponse (struktur data dari basis data) dan data class DataUser (struktur data dari basis data). Untuk memastikan data tersebut tersimpan dan tersedia dengan baik, pada bagian model peneliti perlu menambahkan repository untuk mengatur ketersediaan data dalam sistem dalam bentuk fungsi fun login (parameter masukan data user).

Bagian kedua dari arsitektur MVVM adalah viewmodel, bagian ini memiliki fungsi untuk memperhatikan ketersediaan data dari model. Pertama implementasi dari viewmodel dibuat dengan membuat sebuah variabel seperti private val loginResponse : MutableLiveData<UiState $\langle$ LoginObject.LoginResponse >> = MutableLive
Data( ) dengan tujuan untuk menampung ketersediaan data dari repository. Lalu dilanjutkan dengan membuat sebuah fungsi fun getLoginResponse() : LiveData <UiState<LoginObject.LoginResponse>> = login Response dengan tujuan untuk melihat ketersediaan data dari variabel LoginResponse. Terakhir adalah membuat satu buah fungsi dengan kode fun Login (parameter masukan data dari user)\{respon dari sistem terhadap ketersediaan data\} dengan tujuan untuk menjalankan API sehingga sistem dapat memperoleh data yang diinginkan.

Bagian terakhir dari implementasi arsitektur MVVM pada sistem kehadiran adalah view. Bagian ini bertanggung jawab atas dua hal. Pertama adalah tampilan sistem yang dilihat oleh user dan kedua menjadi pemicu untuk menjalankan API yang ada. Agar API pada backend dapat berjalan, maka bagian view hanya perlu akses dari kelas viewmodel. Akses pertama adalah menjalankan fungsi untuk memperhatikan ketersediaan dengan cara viewmodel.getLoginResponse(). observe(this, Observer \{respon sistem terhadap ketersediaan data\}. Akses kedua adalah menjalankan API dengan kode viewmodel. login (masukan data dari user).

Selain dari mewujudkan fokus maintainability pada proses pengembangan sistem kehadiran. Fokus lain yang perlu dikerjakan pada sistem kehadiran adalah keamanan. Fokus ini dapat dicapai dan dimaksimalkan pada beberapa cara di beberapa bagian. Sehingga nantinya sistem bisa memberikan dampak positif kepada mitra.

Tabel 6. Implementasi Get IMEI Pada Fokus Keamanan

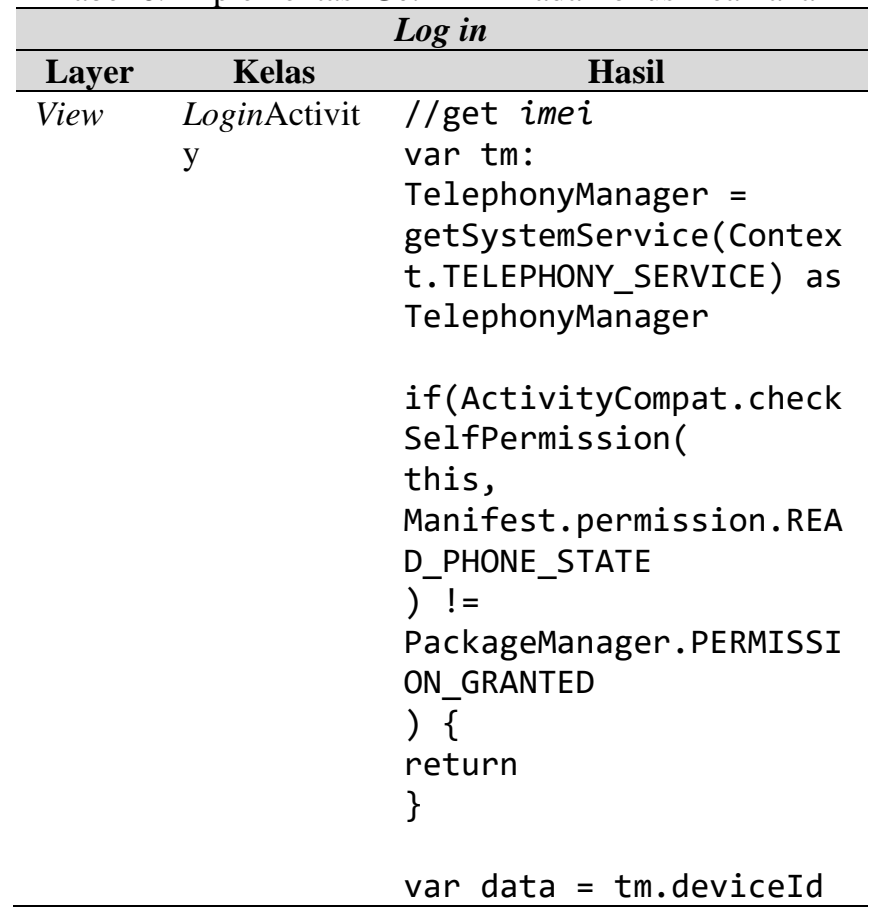

Berdasarkan Tabel 6 implementasi pada fitur $\log$ in tidak hanya terletak pada fokus maintainability. Implementasi pada fitur $\log$ in juga memperhatikan fokus keamanan dengan menambahkan metode tertentu agar sistem dapat membaca device yang digunakan oleh user. Fokus keamanan ini dapat 
dikembangkan dengan cara membuat sebuah variabel dalam bentuk kode var tm: TelephonyManager = getSystemService(Context.TELEPHONY_SERVICE) as TelephonyManager. Variabel ini memiliki fungsi untuk menjadi sebuah metode yang bisa mengakses detail dari perangkat yang digunakan user. Setelah inisialisasi metode tersebut selesai proses selanjutnya adalah memanggil data yang diinginkan lalu disimpan dalam sebuah variabel lain dalam bentuk kode var data $=\mathrm{tm}$. deviceId.

Tabel 7. Implementasi Get Location Pada Fokus Keamanan

\begin{tabular}{|c|c|c|}
\hline \multicolumn{3}{|r|}{ Presence } \\
\hline Layer & Kelas & Hasil \\
\hline View & $\begin{array}{l}\text { HomeFra } \\
\text { gment }\end{array}$ & $\begin{array}{l}\text { private fun } \\
\text { buildLocationCallback() }\{ \\
\text { locationCallback = } \\
\text { object:LocationCallback() } \\
\{ \\
\text { override fun } \\
\text { onLocationResult(p0: } \\
\text { LocationResult) }\{\end{array}$ \\
\hline & & $\begin{array}{l}\text { super.onLocationResult(p0 } \\
\text { ) } \\
\text { val location = } \\
\text { p0.locations.get(p0.locat } \\
\text { ions.size - 1) } \\
\text { lat = location.latitude } \\
\text { lng = location.longitude } \\
\text { \}\}\} }\end{array}$ \\
\hline
\end{tabular}

Pada Tabel 7 implementasi metode get location pada fokus keamanan diletakan pada fitur presence. Implementasi metode get location dilakukan pada layer view sehingga tidak mengganggu fungsi dari model dan viewmodel. Proses implementasi metode ini dimulai dari membuat sebuah fungsi kode private fun buildLocationCallback()\{\}. Sama seperti metode get IMEI sebelumnya metode pemanggilan disimpan dalam sebuah variabel val location = p0.locations.get (p0.locations.size - 1). Ketika inisialisasi metode sudah selesai, maka lokasi dapat dipanggil dan bisa langsung disimpan dalam variabel lain. Untuk data latitude dapat disimpan dalam variabel lat = location. latitude dan longitude dapat disimpan lng = location. longitude.

Bagian terakhir pada fokus keamanan adalah implementasi dari metode JWT Authentication. Berbeda dengan metode get imei dan get location, implementasi pada JWT Authentication ada pada sisi backend. Proses implementasi dikerjakan dengan menggunakan bahasa pemrograman Javasripct pada IDE Visual Studio Code. Implementasi kode tersebut cukup sederhana karena hanya perlu membuat sebuah variabel yang memiliki sebuah metode. var token = jwt.sign ( $\{$ rows $\}$, config.secret); metode tersebut akan menghasilkan sebuah token yang mana tiap user memiliki token yang berbeda-beda dan nantinya akan dijadikan sebagai masukan data ketika ingin menggunakan fitur lain pada sistem kehadiran.

F. System Testing

Proses selanjutnya dari implementasi model pengembangan PXP adalah system testing. Proses uji sistem dikerjakan dengan menyesuaikan detail kegiatan dari proses iteration initialization. Jika rancangan dari fitur tersebut memerlukan data dari basis data melalui API, maka uji sistem berjalan dua kali. Pertama untuk melihat kesesuaian API dan uji kedua adalah melihat hasil uji fitur secara utuh. Apabila sebaliknya maka proses uji sistem hanya akan berjalan sebanyak satu kali.

Tabel 8. Hasil Uji Sistem Pada Sistem Kehadiran

\begin{tabular}{|c|c|c|c|}
\hline $\begin{array}{l}\text { Kode } \\
\text { Fitur }\end{array}$ & $\begin{array}{l}\text { Nama } \\
\text { Fitur }\end{array}$ & Test & Hasil \\
\hline \multirow[t]{6}{*}{$\begin{array}{c}\text { FU- } \\
01\end{array}$} & \multirow[t]{6}{*}{ Log in } & $\begin{array}{l}\text { Masukan password dan } \\
\text { username lengkap dan } \\
\text { benar }\end{array}$ & Terima \\
\hline & & $\begin{array}{l}\text { Masukan data username } \\
\text { kosong }\end{array}$ & Tolak \\
\hline & & $\begin{array}{l}\text { Masukan data password } \\
\text { kosong }\end{array}$ & Tolak \\
\hline & & $\begin{array}{l}\text { Masukan data username } \\
\text { salah }\end{array}$ & Tolak \\
\hline & & $\begin{array}{l}\text { Masukan data password } \\
\text { salah }\end{array}$ & Tolak \\
\hline & & Koneksi internet putus & Tolak \\
\hline \multirow[t]{2}{*}{$\begin{array}{c}\text { FU- } \\
02\end{array}$} & \multirow[t]{2}{*}{$\begin{array}{l}\text { Admin } \\
\text { Contact }\end{array}$} & $\begin{array}{l}\text { Intent dengan koneksi } \\
\text { internet }\end{array}$ & Terima \\
\hline & & $\begin{array}{l}\text { Intent tanpa koneksi } \\
\text { internet }\end{array}$ & Terima \\
\hline \multirow[t]{2}{*}{$\begin{array}{l}\text { FU- } \\
06\end{array}$} & \multirow[t]{2}{*}{ Profile } & $\begin{array}{l}\text { Akses halaman dengan } \\
\text { koneksi internet }\end{array}$ & Terima \\
\hline & & $\begin{array}{l}\text { Akses halaman tanpa } \\
\text { koneksi internet }\end{array}$ & Terima \\
\hline \multirow[t]{6}{*}{$\begin{array}{l}\text { FU- } \\
07\end{array}$} & \multirow[t]{6}{*}{$\begin{array}{l}\text { Password } \\
\text { Change }\end{array}$} & $\begin{array}{l}\text { Masukan data pertama } \\
\text { kosong }\end{array}$ & Tolak \\
\hline & & $\begin{array}{l}\text { Masukan data kedua } \\
\text { kosong }\end{array}$ & Tolak \\
\hline & & Kedua input kosong & Tolak \\
\hline & & Kedua input tidak sesuai & Tolak \\
\hline & & $\begin{array}{l}\text { Proses perubahan } \\
\text { dijalankan tanpa koneksi } \\
\text { internet }\end{array}$ & Tolak \\
\hline & & $\begin{array}{l}\text { Semua input terisi dan ada } \\
\text { koneksi internet }\end{array}$ & Terima \\
\hline \multirow[t]{2}{*}{$\begin{array}{c}\text { FU- } \\
03\end{array}$} & \multirow[t]{2}{*}{ Presence } & $\begin{array}{l}\text { Hadir kerja di kantor } \\
\text { dengan masukan data } \\
\text { lengkap }\end{array}$ & Terima \\
\hline & & $\begin{array}{l}\text { Hadir kerja di luar kantor } \\
\text { dengan masukan data tidak } \\
\text { lengkap }\end{array}$ & Terima \\
\hline
\end{tabular}




\begin{tabular}{|c|c|c|c|}
\hline & & $\begin{array}{l}\text { Hadir kerja di kantor } \\
\text { dengan masukan data tidak } \\
\text { lengkap (lokasi tidak } \\
\text { dipilih) }\end{array}$ & Tolak \\
\hline & & $\begin{array}{l}\text { Hadir kerja di luar kantor } \\
\text { dengan masukan data tidak } \\
\text { lengkap (kegiatan tidak } \\
\text { dimasukan) }\end{array}$ & Tolak \\
\hline & & $\begin{array}{l}\text { Hadir kerja di kantor } \\
\text { dengan data lengkap (tanpa } \\
\text { ada koneksi internet) }\end{array}$ & Tolak \\
\hline & & $\begin{array}{l}\text { Hadir kerja di luar kantor } \\
\text { dengan data lengkap (tanpa } \\
\text { ada koneksi internet) }\end{array}$ & Tolak \\
\hline & & $\begin{array}{l}\text { Hadir kerja di kantor (jarak } \\
\text { terlalu jauh) }\end{array}$ & Tolak \\
\hline $\begin{array}{c}\text { FU- } \\
04\end{array}$ & Absence & $\begin{array}{l}\text { Absence dengan koneksi } \\
\text { internet }\end{array}$ & Terima \\
\hline & & $\begin{array}{l}\text { Absence tanpa koneksi } \\
\text { internet }\end{array}$ & Tolak \\
\hline $\begin{array}{c}\text { FU- } \\
05\end{array}$ & $\begin{array}{l}\text { Track } \\
\text { Record }\end{array}$ & $\begin{array}{l}\text { Memperoleh data dengan } \\
\text { masukan data lengkap }\end{array}$ & Terima \\
\hline & & $\begin{array}{l}\text { Memperoleh data dengan } \\
\text { masukan data tidak } \\
\text { lengkap }\end{array}$ & Terima \\
\hline & & $\begin{array}{l}\text { Memperoleh data dengan } \\
\text { masukan data lengkap } \\
\text { (tanpa koneksi internet) }\end{array}$ & Tolak \\
\hline & & $\begin{array}{l}\text { Memperoleh detail data } \\
\text { dengan masukan data } \\
\text { lengkap }\end{array}$ & Terima \\
\hline & & $\begin{array}{l}\text { Memperoleh detail data } \\
\text { dengan masukan tidak data } \\
\text { lengkap }\end{array}$ & Tolak \\
\hline & & $\begin{array}{l}\text { Memperoleh detail data } \\
\text { dengan masukan data } \\
\text { lengkap (tanpa koneksi } \\
\text { internet) }\end{array}$ & Tolak \\
\hline & & $\begin{array}{l}\text { Ubah data kegiatan dengan } \\
\text { masukan data dan tanggal } \\
\text { seusai hari }\end{array}$ & Terima \\
\hline & & $\begin{array}{l}\text { Ubah data kegiatan dengan } \\
\text { masukan data dan tanggal } \\
\text { tidak sesuai hari }\end{array}$ & Tolak \\
\hline & & $\begin{array}{l}\text { Ubah data kegiatan dengan } \\
\text { masukan data dan tanggal } \\
\text { (tanpa koneksi internet) }\end{array}$ & Terima \\
\hline
\end{tabular}

Berdasarkan dari Tabel 8 implementasi system testing pada sistem kehadiran dilakukan dengan menggunakan metode black box. Proses uji sistem dilakukan dengan melihat kondisi sistem ketika mendapatkan masukan data dan berjalan dalam dua kondisi berbeda. Kondisi pertama adalah masukan data yang sesuai serta memiliki koneksi internet dan kondisi kedua di mana sistem mendapat masukan data yang tidak sesuai dan tidak memiliki koneksi internet. Secara garis besar dari dua skenario kejadian di atas hasil didapat menunjukan sistem berjalan dengan baik dan berjalan sesuai rancangan. Apabila masukan data dan sistem berjalan sesuai maka sistem dapat berjalan atau bekerja dengan baik dan jika yang terjadi sebaliknya maka sistem tidak akan bekerja dengan baik.

Melalui dua skenario kejadian yang telah dijelaskan sebelumnya, maka hasil dari system testing terbagi menjadi dua. Iterasi yang dijalankan dengan model kejadian skenario pertama mendapatkan hasil "Terima" dan apabila yang terjadi pada iterasi tersebut adalah sebaliknya maka hasil menjadi "Tolak". Sehingga dari kedua hasil tersebut peneliti dapat menyimpulkan bahwa sistem berjalan dengan baik karena sistem memberikan respon sesuai dengan masing-masing skenario pada tiap iterasi.

\section{G. Retrospective}

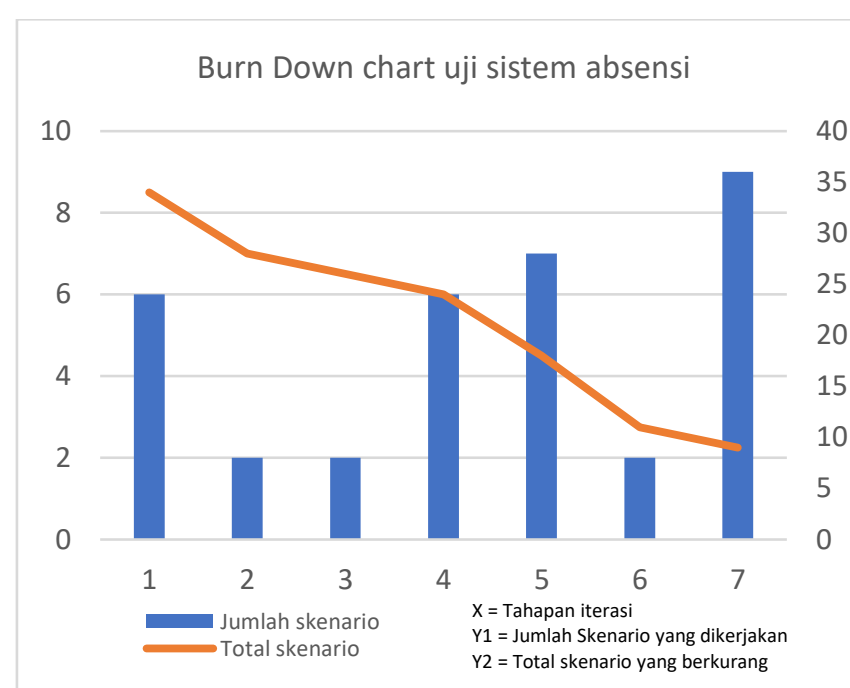

Gambar 6. Hasil Total Uji Sistem Dari Tiap Iterasi

Berdasarkan Gambar 6 secara garis besar hasil implementasi pada sistem kehadiran dapat disimpulkan dengan membuat burndown chart. Nilai dari sumbu X adalah tahapan iterasi pada system testing, nilai dari sumbu Y1 adalah jumlah skenario yang diuji pada tiap iterasi, dan Y2 adalah sisa total skenario yang ada pada tiap iterasi. Melalui gambaran informasi yang ada pada burndown chart maka dapat dilihat bahwa semakin banyak uji skenario yang dilakukan mendapatkan hasil sesuai dari uji skenario, semakin berkurang pula total uji skenario yang harus dilakukan. Dengan demikian pada akhir implementasi sistem kehadiran nilai dari total uji skenario akan sama dengan nilai uji skenario pada system testing.

\section{KESIMPULAN DAN SARAN}

A. Kesimpulan

Adapun kesimpulan yang dapat ditarik pada pengembangan sistem kehadiran online PT. Lintasmaya Network dengan memperhatikan arsitektur MVVM dan model pengembangan Personal Extreme Programming yaitu implementasi metode PXP dan arsitektur MVVM memungkinkan fokus maintainability tercapai karena proses 
pengembangan yang terstruktur dan terdokumentasi dengan baik di tiap proses dan bagian sistem. Implementasi IMEI, get location, dan JWT Authentication memungkinkan sistem presensi menjadi lebih aman karena sistem kehadiran hanya dapat digunakan oleh yang memiliki kepentingan saja dengan hasil data yang akurat.

\section{B. Saran}

Terkait dengan saran yang dapat disampaikan oleh peneliti kepada pembaca dan mitra untuk pengembangan sistem kehadiran kedepannya adalah membuat sistem menjadi tersedia pada sistem operasi lain seperti iOS. Selain itu perlu dibuat sistem presensi yang memiliki tampilan lebih baik dengan memperhatikan UI dan UX dalam pengembangan berikutnya.

\section{REFERENSI}

[1] Eka, S.V. (2018). Strategi Indonesia Menghadapi Industri 4.0. Info Singkat, Vol. X(09), pp. 19-24.

[2] Setiawan, P.R. (2020). Aplikasi Absensi Online Berbasis Android. IT Journal Research and Development, Vol.5(1), pp. 63-71.

[3] Putera, A.P. (2020). Rancang Bangun Aplikasi Absensi Online Berbasis Android Menggunakan Metode Deep Learning Pada PT. Pelabuhan Indonesia III (Persero) [Skripsi]. Universitas 17 Agustus 1945 Surabaya.
[4] Febriandirza, A. (2020). Perancangan Aplikasi Absensi Online Dengan Menggunakan Bahasa Pemrograman Kotlin. Jurnal Pseudocode, Vol. 7(2), pp. 123-133.

[5] Subiantoro \& Sardiarinto. (2018). Perancangan Sistem Absensi Pegawai Berbasis Web. Jurnal Swabumi, Vol. 6(2), pp. 184-189.

[6] Reza. (2020). Sistem Absensi. (A. Setiawan, Interviewer).

[7] Marthasari, G., Suharso, W. \& Ardiyansyah, F. (2018). Personal Extreme Programming with MoSCoW Prioritization for Developing Library Information System. Proceeding of the Electrical Engineering, Computer Science, and Informatics, Vol. 5(51).

[8] Syeikh, W. \& Syeikh, N. (2019). A Model-ViewViewmodel (MVVM) Application Framework For Hearing Impairment Diagnosis. The Journal of Open Source Software. DOI: 10.21105/joss.02016.

[9] Sai, P. (2018). Multi-Factor Authentication Using IMEI Encrypted Color QR Code. International Journal of Pure and Mathematics, Vol. 119(15), pp. 1713-1719.

[10] Pribadi, J.A. \& Setiyawati, N. (2021). AbsenLoc: Aplikasi Absensi Mobile Berbasis Lokasi. Jurnal Sistem dan Teknologi Informasi, Vol. 9(1), pp. 33-40. DOI: 10.26418/justin.v9i1.41103.

[11] Gunawan, R. \& Rahmatulloh, A. (2019). JSON Web Token (JWT) Untuk Authentication Pada Interoperabilitas Arsitektur Berbasis RESTful Web Service. Jurnal Edukasi dan Penelitian Informatika, Vol. 5(1), pp. 74-79. 